\section{Enamel Protein}

HUman dental enamel contains about one per cent organic matter ${ }^{1}$, and it is well established on histological evidence that the structure of enamel consists of a mesh-work of organic matter in which inorganic salts (mainly calcium phosphate) are deposited in an orderly arrangement, resembling prisms. It is to be noted that newly formed enamel is covered with a layer of organic matter (Nasmyth's membrane), and also ${ }^{2}$ that there is more organic matter in enamel near the junction with the underlying tissue, the dentine, than in that portion equidistant from the dentine and the surface of the tooth.

Fifty years ago Thompson ${ }^{3}$, in describing human dental enamel, referred to "an organic matrix of horny matter, keratine", and it may be said that the organic matter associated with enamel has always been regarded as keratin. Most authorities agree in referring to keratins as proteins with a high sulphur content, although Block and Vickery ${ }^{4}$ do not regard "a high proportion of cystine as necessarily characteristic of keratins". It has been stated that "the linkages binding sulphur into the protein molecule are uncertain"s; this uncertainty may be said to extend to organic substances containing sulphur, of which two new examples have recently been described by Mueller ${ }^{6}$ and Baernstein ${ }^{7}$. It will be seen below that the presence of sulphur can readily be demonstrated in some keratins, but it may be said that the demonstration is incomplete so far as enamel protein is concerned. Rosebury ${ }^{8}$, who recently published a detailed study of enamel protein, described it as "showing the chemical characteristics of keratin". In this work he used the lead test for labile sulphur, which, he says, "at best is not a delicate reaction".

In separating the organic material in enamel from the inorganic part, one of the difficulties with which I met was the scarcity of suitable human material. It was considered that biochemical methods of examination into the nature of this protein offered advantages over methods involving the use of stains and microscopy. One method of separation of the inorganic matter from the organic consists of reducing whole teeth to powder, then suspending the mass in a liquid of which the relative density is midway between that of the inorganic and the organic portions. This method was not continued as it was found that the density of the organic matter in dentine was too near that of the organic matter in enamel.

I took advantage of the fact that the inorganic salts of enamel are soluble in acetic acid, while the organic part appears to be insoluble. While this means of separating organic matter from in. organic has been found convenient, it is realized that the acid may have some action on the protein. For the purposes of the present work, it has been assumed that acetic acid does not dissolve organic matter from the dentine. This assumption is supported by histological evidence.

In an attempt to elucidate the nature of enamel protein, the following method was used: sound (non-carious) human teeth were scraped clean, dipped in 20 per cent nitric acid for a few seconds to remove surface contamination, and washed in distilled water. The roots were cut off and discarded, and any remaining pulp-tissue removed. The crowns were next exposed to the action of 10 per cent acetic acid as a decalcifying agent and agitated mechanically for twelve days. In this way the greater part of the enamel was removed from the dentine and appeared in the acid as a white powder, separation being aided by shaking with glass beads. The pieces of dentine were removed, and the white powder allowed to settle for 24 hours, when the bulk of the fluid was poured off and tested for protein with picric acid and with sulpho-salicylic acid, both with negative results. The powdery mass was next shaken up with distilled water and a few drops of nitric acid added. The enamel protein was thrown out by centrifuging, then washed and centrifuged several times until the washings appeared noutral to B.D.H. universal indicator.

The applieation of this method resulted in the separation of the protein as a flocculent, yellowish. brown mass, with a density near that of water. Nitrogen determination gave a positive result, but the percentage figure arrived at $(9 \cdot 2)$ is of doubtful value on account of uncertainty as to the freedom from contamination of the protein. Heated on platinum foil to redness, the protein disappeared leaving only the faintest of marks. It appeared unchanged after exposure for one hour to boiling strong potassium hydroxide. With Millon's reagent the protein gave a marked red colour. Negative results were seen when the sodium nitro-prusside test for sulphur as given by $\mathrm{Cole}^{2}$ was applied. The procedure was varied by exposing the protein to 1 per cent potassium hydroxide at $37^{\circ} \mathrm{C}$. for twenty-four hours, and also by boiling it with 25 per cent potas. sium hydroxide for one hour. The sodium nitroprusside test gave a negative result after both these forms of treatment. As controls, fragments of human nail, sheep's wool and horse hoof were exposed to acetic acid for ten days and then tested for sulphur by the nitro-prusside method, with a positive result in each case. Other reducing agents were used in attempts to reduce any cystine present to cysteine : tin exposed to hydrochloric acid, also zine exposed to cadmium chloride then to hydrochloric acid. Both these reducing agents were used in place of potassium cyanide, but gave negative results. It was noticed, however, that when potassium cyanide was used as a reducing agent, the protein went into solution.

It is thought that it should be possible to get the protein in a pure form by the use of potassium cyanide followed by the use of dialysis. The observation that the action of potassium cyanide is to dis. solve this protein may be contrasted with the negative results observed with the nitro-prusside method. It is thought that neither the acetic acid used to de. calcify the teeth, nor the presence of calcium salts from the enamel or the dentine affected the result. Preliminary examination of the protein by $\mathbf{M r}$. W. T. Astbury using X-ray spectrography has suggested that the $\mathrm{X}$-ray picture differs from that given by some keratins.

The organic material appears to be a protein containing tyrosin and resembling reticulin, and further work to determine its nature is in progress.

The work was earried out with the aid of a grant from the Medical Research Council, for which grateful acknowledgement is made.

Paul Prncus.

John Hampton Hale Research Laboratory, Royal Dental Hospital, London.

\footnotetext{
1 Bowes and Murray, Biochem, J., 29, 12, 2721 (1935).

C. F. Bodecker, J. Dent. Res., 6, 2,117 (1923)

${ }^{3}$ A. H. Thompson, Amer, J. Dent. Soc, 20433 (1887).

- Block and Vickery, J. Biol. Chem., 93, 1, 113 (1931).

¿ D. Jordan Lloyd "Chemistry of Proteing" (London, 1926).

- J. H. Mueller, 'J'Biol Chem, 56, 157 (1923).

' T. Baernstein, J. Biol. Chem., I15, No. 1, p. 25 (1936).

- S. W. Cole, "Pract. Physiol. Chem." (Cambridge, 1933).
} 